\title{
LA CENTRALIZACIÓN DEL CAPITAL: PROCESO DETERMINANTE EN LA TRANSNACIONALIZACIÓN DEL CAPITALISMO CONTEMPORÁNEO
}

\author{
CENTRALIZATION OF CAPITAL: DETERMINANT PROCESS IN THE \\ TRANSNATIONALIZATION OF CONTEMPORARY CAPITALISM \\ A CENTRALIZAÇÃO DO CAPITAL: PROCESSO DETERMINANTE NA \\ TRANSNACIONALIZAÇÃO DO CAPITALISMO CONTEMPORÂNEO
}

\author{
Por: SILVA COLMENARES - Julio, PADILLA PARDO - Carolina
}

\begin{abstract}
PhD en economía (summa cum laude) de la Escuela Superior de Economía de Berlín y doctor en ciencias económicas de la Universidad de Rostock (Alemania); Miembro fundador y de número y presidente de la Academia Colombiana de Ciencias Económicas; miembro correspondiente de la Real Academia de Ciencias Morales y Políticas de España y de la Academia Nacional de Economía del Uruguay; profesor-investigador y director del Observatorio sobre Desarrollo Humano de la Universidad Autónoma de Colombia; obdehumano@fuac.edu.co

Especialista en gerencia financiera; cursante de la maestría (a distancia) en desarrollo humano de FLACSO, Argentina; profesional en relaciones económicas internacionales y economista, adscrita al Observatorio sobre Desarrollo Humano de la Universidad Autónoma de Colombia. auxobdehum@fuac.edu.co rei.carolina.pp@gmail.com
\end{abstract}

\begin{abstract}
RESUMEN
Mientras diversas corrientes del pensamiento económico ven todavía a la libre competencia como el cimiento del capitalismo actual y a los monopolios $u$ oligopolios como fallas de mercado, en este artículo se sostiene la hipótesis de que la competencia promueve los procesos de concentración de la producción y centralización del capital que dan origen a una fase monopolista del capitalismo en la que surgen grandes empresas, en forma de grupos financieros o conglomerados empresariales, que trascienden las fronteras nacionales y tienen capacidad para incidir en las condiciones que determinan el encuentro entre oferentes y demandantes. Este fenómeno no es exclusivo de los países ricos sino que también se presenta en países pobres caracterizados por un «capitalismo dependiente y tardío», sin libre competencia pero con una fuerte presencia de oligarquía financiera. La transnacionalización de empresas colombianas permite exponer un ejemplo práctico de lo anterior.
\end{abstract}

Palabras clave: monopolios, oligopolios, empresas transnacionales, grupos financieros.

JEL: F21, F23, L12, L13, L22 


\begin{abstract}
While several currents of economic thought still see free competition as the foundation of contemporary capitalism and monopolies either oligopolies as market failures, in this article the hypothesis holds that competition promotes the processes of concentration of production and centralization of capital that give rise to a monopoly stage of capitalism in which large companies emerge in the form of financial groups or conglomerates, which transcend national borders and have the capacity to influence the conditions that determine the encounter between suppliers and consumers. This phenomenon is not exclusive to rich countries but also occurs in poor countries characterized by a «late and dependent capitalism», without competition but with a strong presence of financial oligarchy. The transnationalization of Colombian companies can expose a practical example of this.
\end{abstract}

Key words: monopolies, oligopolies, transnational corporations, financial groups.

JEL: F21, F23, L12, L13, L22

\title{
RESUMO
}

Enquanto diversas correntes do pensamento econômico ainda concebem à livre concorrência como o pilar do capitalismo atual, assim como entendem os monopólios ou oligopólios como falhas do mercado, neste trabalho apresentase a hipótese de que a competência promove os processos de concentração da produção e centralização do capital que originam uma fase monopolista do capitalismo na qual emergem grandes empresas, na forma de grupos financeiros e conglomerados empresariais, os quais, por sua vez, transcendem as fronteiras nacionais e têm a capacidade de incidir nas condições de encontro entre oferentes e demandantes. Este fenômeno não é exclusivo dos países ricos, apresentando-se, também, nos países pobres caraterizados por "capitalismo dependente e tardio", sem livre concorrência, mas com uma forte presença da oligarquia financeira. A transnacionalização das empresas colombianas é um exemplo prático do descrito anteriormente.

Palavras-chave: monopólios, oligopólios, empresas transnacionais, grupos financeiros.

JEL: F21, F23, L12, L13, L22

\section{LA CONCENTRACIÓN DE LA PRODUCCIÓN Y LA CENTRALIZACIÓN DEL CAPITAL}

La transnacionalización de empresas, esto es, su traslado, con presencia directa, a otras economías o países distintos a los de su origen, lo que ocurre desde hace más de un siglo en el mundo capitalista, no se puede comprender bien si no se conoce lo esencial del proceso que les permitió «exportar» capital en forma de inversiones directas en el exterior, con sus efectos, tanto en los países de origen como en los receptores, de esa «exportación». Para comenzar, hay que mencionar la acumulación, sobre la cual Carlos Marx (1818-1883) formuló a mediados del 
siglo $19^{1}$ lo que llamó la ley general, absoluta, de la acumulación capitalista, de la siguiente manera: Cuanto mayores son la riqueza social, el capital en funciones, el volumen y la intensidad de su crecimiento y mayores también, por tanto, la magnitud absoluta del proletariado y la capacidad productiva de su trabajo, tanto mayor es el ejército industrial de reserva. La fuerza de trabajo disponible se desarrolla por las mismas causas que la fuerza expansiva del capital. (...) Una ley que, como todas las demás, se ve modificada en su aplicación por una serie de circunstancias que no interesa analizar aquí (Marx, 1946: 546-547). Si bien la lucha organizada de los trabajadores durante el siglo 20 impidió que se llegase a este «dantesco» resultado de creciente desempleo que empobrece a los trabajadores, la lógica del desarrollo capitalista se mantiene, por cauces menos violentos.

Esa lógica lleva a que la acumulación desemboque en la concentración de la producción, con el incremento en el tamaño de las unidades productoras y, por tanto, en la posibilidad de que uno o varios productores puedan determinar algunas condiciones en el respectivo mercado. Este proceso ya lo había entrevisto en la segunda parte del siglo 18 el filósofo escocés Adam Smith (1994: 191 y 215) considerado uno de los fundadores de la Economía Política. Si bien definió a la competencia como una «mano invisible» que podía llevar a la mejor asignación de los recursos para beneficio común, así no fuese ese el interés de sus propietarios, también vio el peligro del monopolio. Como escribió en su libro sobre La riqueza de las naciones, "Es raro que se reúnan personas del mismo negocio, aunque sea para divertirse y distraerse, y que la conversación no termine en una conspiración contra el público o en alguna estratagema para subir los precios. (...)”. Y un poco más adelante insiste en que el "monopolio, asimismo, es el peor enemigo de la buena administración, que nunca puede establecerse de forma generalizada si no es a consecuencia de esa competencia libre y universal que fuerza a cada uno a recurrir a ella por su propio interés. (...)”. Como lo demuestra multitud de ejemplos, tales conspiraciones son de ocurrencia diaria en la sociedad moderna, incluso con la mirada permisiva del Estado.

Pero tampoco es un fenómeno reciente; ya lo había vislumbrado Aristóteles (384-322 a.n.e. ${ }^{2}$ ) en la Grecia antigua. En la sociedad moderna, casi un siglo después de Smith, Marx verá de manera más clara esta negación dialéctica de la competencia, aunque no pudo escribir en concreto sobre el paso del capitalismo a su fase monopolista, ya que falleció cuando apenas se iniciaba esta transformación. En su polémica con Proudhon describió la dialéctica que lleva de la competencia al monopolio y al predominio de éste sin eliminar del todo aquella, como es el rasgo característico del capitalismo contemporáneo; según sus palabras, "En la vida práctica no solamente se encuentran la competencia, el monopolio y su antagonismo, sino también su síntesis, que no es una fórmula, sino un movi-

1 Si bien la Gramática de las Academias de la lengua española recomienda escribir los siglos con números romanos, se prefiere hacerlo con números arábigos, como ya se hace en otros idiomas, pues se considera a la numeración romanesca como desueta y confusa para el lector normal.

2. a.n.e.= Antes de nuestra era o era cristiana, aunque no hay coincidencia sobre el año en que ocurrió el evento que se ha tomado como inicio de esta era, pues también se discute la existencia real de Cristo. 
miento. (...) Los monopolios surgen de la competencia, los competidores se hacen monopolizadores. (...) La síntesis es tal que el monopolio sólo puede mantenerse pasando continuamente por la lucha de la competencia” (Marx, 1958: 130-131).

Por la misma época, en El manifiesto comunista se encuentra una vívida descripción de la primera revolución industrial y lo que significó como desarrollo de las fuerzas productivas y avance hacia un mercado mundial, proceso que aún continúa y cuya marcha se ha acelerado, impulsada por las revoluciones industriales siguientes, en especial con la aplicación de la electrónica y los cambios en las comunicaciones, impensables hace siglo y medio. Como plantean Marx y Engels, luego del "descubrimiento de América y la circunnavegación de África, (...) el vapor y la maquinaria revolucionaron (...) la producción industrial. La gran industria moderna sustituyó a la manufactura (...) La gran industria ha creado el mercado mundial (...) El mercado mundial aceleró prodigiosamente el desarrollo del comercio, de la navegación y de los medios de transporte por tierra”. Y eso que ni siquiera se discutía la posibilidad del transporte aéreo y la comunicación inalámbrica.

Con estas frases Marx y Engels entrevieron también lo que se conoce hoy como la internacionalización o «transnacionalización» del proceso de producción y consumo, que ha adquirido características inimaginables no sólo hace siglo y medio sino apenas unas décadas atrás. Como decían Marx y Engels, la producción y el consumo tienden a tener un carácter cosmopolita. "Con gran sentimiento de los reaccionarios", la industria pierde su base nacional. "Las antiguas industrias nacionales (...) son suplantadas por nuevas industrias, (...) que ya no emplean materias primas indígenas, sino materias primas venidas de las más lejanas regiones del mundo, y cuyos productos no sólo se consumen en el propio país, sino en todas las partes del mundo. En lugar de las antiguas necesidades, satisfechas con productos nacionales, surgen necesidades nuevas, que reclaman para su satisfacción productos de los países más apartados y de los climas más diversos (...)" (1973: 114-123).

Con la ampliación del mundo conocido por los europeos en el siglo 15 y el inicio del capitalismo en el siglo 16, el desarrollo de la sociedad humana se hizo más complejo y ha estado sujeto a múltiples y variados ciclos, que han ido desde los que tienen como escenario un solo país o región, con poca intensidad y corto tiempo, hasta los de mayor envergadura y duración, que abarcan diversos países o regiones y duran varios años o lustros, verdadera manifestación de la globalización que se vive desde la edad media europea.

Si se regresa al siglo 19, el gran mérito de Marx fue haber puesto en evidencia que en el propio proceso de acumulación se encuentran los factores de la transformación que lleva al capitalismo monopolista. Como escribió Marx, "No se trata ya de una simple concentración, idéntica a la acumulación, de los medios de producción y del poder de mando sobre el trabajo. Se trata de la concentración de los capitales ya existentes, de la acumulación de su autonomía individual, de la expropiación de unos capitalistas por otros, de la aglutinación de muchos capitales pequeños para formar unos cuantos capitales grandes. Este proceso se distingue del primero en que sólo presupone una distinta distribución de los capitales ya 
existentes y en funciones; en que, por tanto, su radio de acción no está limitado por el incremento absoluto de la riqueza social o por las fronteras absolutas de la acumulación. El capital adquiere, aquí, en una mano, grandes proporciones porque allí se desperdiga en muchas manos. Se trata de una verdadera centralización, que no debe confundirse con la acumulación y la concentración".

De acuerdo con la percepción de Marx en ese momento, "la concurrencia -diceactúa vertiginosamente en razón directa al número y en razón inversa al volumen de los capitales que rivalizan entre sí. Y termina siempre con la derrota de los muchos capitalistas pequeños, cuyos capitales son engullidos por el vencedor, o desaparecen”. Y más adelante enfatiza: “(...) Dentro de una determinada rama industrial, la centralización alcanzaría su límite máximo cuando todos los capitales invertidos en ella se aglutinasen en manos de un solo capitalista. (...) La centralización completa la obra de la acumulación, puesto que permite a los capitalistas industriales extender la escala de sus operaciones. (...) Pero es evidente que la acumulación, o sea, el incremento paulatino del capital mediante la reproducción, que abandona su forma circular para desarrollarse en espiral, es un proceso harto lento, comparado con la centralización, a la que le basta con modificar la agrupación meramente cuantitativa de las partes que integran el capital social”. A lo que Engels añadió la siguiente nota de pie de página en la cuarta edición del primer tomo de El Capital: "Los novísimos trusts ingleses y norteamericanos aspiran ya a esto, puesto que tienden a unificar, por lo menos, todas las grandes empresas de una rama industrial, en una gran sociedad anónima con monopolio efectivo" (Marx, 1946:529-531). Pero el desarrollo posterior del capitalismo mostró que los mismos capitalistas evitaron llegar a esta situación extrema, buscando diversas modalidades que «encubren» la centralización, como tener varias empresas de una misma rama o actividad económica que, a pesar de su independencia formal, responden a un centro común de orientación estratégica, como es el caso del conglomerado moderno. Lo que no niega que esos gigantes empresariales hayan desarrollado los medios para «manipular» en su favor el proceso de reparto del ingreso nacional entre el capital y el trabajo.

Para comprender mejor este proceso, es necesario recordar que desde los inicios de la primera revolución industrial ha aumentado el ritmo de la concentración de la producción y la centralización en la propiedad de los medios de producción -fenómeno, este último, característico de las sociedades con propiedad privada, y que se agudizó desde la primera parte del siglo XX, dando nacimiento a los gigantes empresariales-, estimulado por la acelerada introducción de ciencia y tecnología a la producción, lo que llevó de manera rápida al capitalismo a la transición a la fase monopolista, con los resultados que ello ha acarreado.

Un conocido Diccionario de Economía Política define así, de manera más amplia, estos procesos. La concentración de la producción es un "fenómeno en virtud del cual una parte cada vez mayor de los medios de producción, de la fuerza de trabajo y de la elaboración de mercancías se centra en grandes empresas. En el régimen capitalista, el fenómeno tiene lugar a lo largo de una durísima competencia entre los capitalistas, a la caza de beneficios. Concentrando en alto grado los medios de producción y la mano de obra, los capitalistas reducen sensiblemente los costos de producción, utilizan con mayor amplitud la nueva técnica, organizan la 
producción masiva en cadena, aumentan el volumen y el grado de explotación de la clase obrera. (...)”. En cambio, la centralización del capital es el "crecimiento del volumen del capital por la unión de varios capitales en uno solo o por la absorción de uno de ellos por otro. Este proceso significa que entre los capitalistas se redistribuyen capitales ya acumulados. La particularidad del proceso de centralización del capital estriba en que tal proceso refleja relaciones sobre todo entre los propios capitalistas. (Borisov, Zhamín y Makarova, 1975: 26 y 38).

Si de un lado la centralización del capital impulsa la acumulación en manos de las grandes empresas -por cuanto mayor sea un capital, mayor es el grado con que acumula-, por el otro, la ruina de los pequeños y medianos capitalistas agudiza la contradicción entre la producción y el consumo, pues la demanda solvente cae, no solo por la desaparición como agentes económicos de cientos o miles de pequeños y medianos empresarios, sino también de cientos o miles de trabajadores, cuyos puestos de trabajo desaparecen por la elevación de la productividad que conlleva la gran empresa. Son empresarios y trabajadores que desaparecen en tal condición, para transformarse en «personas sobrantes», que se degradan en la escala social, la que hay que ver con la necesaria perspectiva temporal: las condiciones de vida de los trabajadores de hoy son muy diferentes a las condiciones de hace un siglo o más. He aquí otro de los aportes del marxismo a la comprensión del papel de los monopolios en la crisis del capitalismo y que Marx sólo entrevió, dejando el análisis en profundidad a sus continuadores. Similar observación metodológica hay que hacer sobre sus descubrimientos respecto al valor, el precio y la ganancia.

Para sintetizar, podría decirse que la concentración de la producción expresa la reproducción ampliada, es decir, supone el crecimiento económico, el acrecentamiento de la riqueza para convertir una parte de ella en nuevo capital; expresa las relaciones de producción entre los trabajadores y los capitalistas. En cambio, la centralización del capital no depende tanto de la acumulación, ya que al expresar la diferenciación de los capitalistas es un mecanismo de redistribución del capital en funcionamiento.

\section{DE LA CONCENTRACIÓN Y LA CENTRALIZACIÓN AL CAPITAL MONOPOLISTA}

Como es obvio, mientras diversas corrientes del pensamiento económico ven todavía a la libre competencia como el cimiento del capitalismo actual, quienes siguen a Marx, sin negar la competencia, ven su superación dialéctica y hablan del capitalismo monopolista. Pero hay que tener en cuenta que la gran empresa, per se, no es un monopolio, sino sólo manifestación de la concentración de la producción, o sea, es un fenómeno que se da en el ámbito del proceso de producción. Pero aunadas, la concentración de la producción y la centralización del capital, si dan la posibilidad del monopolio, como un tipo nuevo de relación social que se establece en otro ámbito, en el mercado, en donde uno o varios grandes productores tienen la capacidad de determinar algunas de las condiciones en que se da la relación entre oferta y demanda o, mejor, entre ofertantes y demandantes.

Marx señaló también las vías principales que seguiría la formación de los monopolios, cuando indicó que así se haga la centralización "por la vía de la violencia, en forma de anexión -lo que acontece cuando ciertos capitales se convierten 
en centros tan absorbentes de gravitación para otros, que rompen su cohesión individual, asimilándose luego sus trozos sueltos-, o mediante la fusión de una multitud de capitales ya formados o en curso de formación, siguiendo la senda lisa y llana de la creación de sociedades anónimas, el efecto económico es siempre el mismo". Incluso precisó los que hoy se conocen como los conglomerados, los grupos financieros y las empresas transnacionales.

Por la misma época, Engels dirá que "hoy, las funciones sociales del capitalista corren todas a cargo de empleados a sueldo, y toda la actividad social de aquél se reduce a cobrar sus rentas, cortar sus cupones y jugar en la Bolsa, donde los capitalistas de toda clase se arrebatan unos a otros sus capitales. Y si antes el modo capitalista de producción desplazaba a los obreros, ahora desplaza también a los capitalistas, arrinconándolos, igual que a los obreros, entre la población sobrante; aunque por ahora todavía no en el ejército industrial de reserva" (Engels, 1976: 152-153).

Ya en el desarrollo concreto del capitalismo el fenómeno de la ascendente centralización que llevase a una o muy pocas empresas que sea fácil identificar como controlantes de una actividad, no ha funcionado como en la previsión de Marx y Engels, pues es contrarrestado desde el punto de vista económico por el fraccionamiento artificial de las empresas, según conveniencia de los capitalistas. Hoy en día es frecuente ver que se controla toda una rama o un renglón, esto es, de hecho se tiene un monopolio, pero manteniendo la independencia jurídica y administrativa de las empresas. Desde hace más de un siglo el capitalismo ha encontrado diversos métodos para simular ${ }^{3}$ la competencia. Para el caso de Colombia pueden mencionarse varios ejemplos, pero dos o tres de la industria bastan por ahora: la producción y distribución de azúcar, cemento, cervezas y bebidas gaseosas ${ }^{4}$. Y no se hable del sector financiero, en donde los bancos de dos conglomerados controlan más del 50\% de esa actividad.

De otro lado, también la figura de la moderna oligarquía financiera fue retratada por Marx y Engels. Marx hablaba -al mostrar el papel del crédito en la producción capitalista-, de "una nueva aristocracia financiera, una nueva clase de parásitos en forma de proyectistas, fundadores de sociedades y directores puramente nominales: todo un sistema de especulación y de fraude con respecto a las fundaciones de sociedades y a la emisión y al tráfico de acciones. (Marx, 1946: 417)...)”. Como podría decirse parafraseando el lenguaje de la literatura de ficción, cualquier parecido con el papel de esa aristocracia financiera en diversas crisis ocurridas en los últimos lustros no es simple coincidencia, sino corroboración de una característica ya casi bicentenaria de la sociedad capitalista, pues hasta en la realidad colombiana la hemos encontrado repetidas veces ${ }^{5}$. Esta comprobación para el caso

3. El Diccionario de las Academias de la Lengua Española define el verbo simular como "Representar algo, fingiendo o imitando lo que no es".

4. Véase de Silva-Colmenares Julio. Los verdaderos dueños del país. Oligarquía y monopolios en Colombia. Suramérica, Bogotá, 1977, pp. 46 a 57 y El gran capital en Colombia. Proyección al siglo XXI, Planeta, Bogotá, 2004, pp. 55 a 65 y 195 a 206.

5. En la historia reciente de Colombia el caso de Interbolsa es un ejemplo al respecto. 
colombiano, expuesta en varios libros citados en este artículo, evidencia que este proceso también ha estado presente en los países de la llamada periferia capitalista, quizá en forma más precoz y profunda. Por tanto, no es reciente, esporádico o circunstancial, ni exclusivo de algunos países, lo que no niega que haya tenido diferente periodicidad o intensidad en unas u otras sociedades. Además, para su conocimiento no basta conocer sus efectos -por ejemplo, medir la acumulación del capital o la distribución del ingreso-, sino hay que investigar sobre las causas que lo explican.

Al llegar el siglo 20, cuando se pasa al predominio del capital financiero-fusión de diferentes tipos de capital, en especial comercial, industrial y bancario-, ese movimiento cíclico adquiere nuevas características, manifestándose cada vez en formas más entrelazadas y, por consiguiente, haciéndose más difícil desentrañar su naturaleza intrínseca y hallar salidas. Estaría haciéndose evidente una creciente incapacidad para encontrar soluciones a las dificultades del capitalismo, no obstante que el conocimiento sobre la sociedad aumenta en forma impresionante, por lo que se harían necesarias transformaciones sociales profundas que llevarían a la humanidad de una «época de cambios» a un «cambio de época».

También caracterizó al capital financiero del siglo 20 el incremento ficticio de operaciones de cambio en que no participan bienes reales -y por lo tanto no se crea valor o sólo se crea en una magnitud ínfima-, lo que ha exacerbado el uso del dinero, creando la ilusión de una actividad económica pujante. Se considera que un alto porcentaje de las transacciones que ocurren hoy no están relacionadas con la satisfacción real de las necesidades humanas. Por tanto, el fin último de la actividad económica, que es el consumo para satisfacer las necesidades materiales, sociales y espirituales de los seres humanos, es reemplazado por la producción y circulación de bienes y servicios, en donde el dinero pierde su condición primigenia de mercancía universal para el intercambio y se convierte en medio de enriquecimiento y atesoramiento. Además, con el capitalismo financiero nació, de la libre competencia, el manejo monopolístico de la oferta y los precios, la antítesis que niega, de manera dialéctica, la esencia del capitalismo y lleva el germen de su transformación, mientras que los capitalistas individuales, que al mismo tiempo eran empresarios, se transformaron en capitalistas colectivos y luego en las grandes empresas transnacionales, administradas por gerentes burócratas que tienen sus propios intereses pecuniarios. Recordando a Marx, podría decirse que el capitalismo sigue cavando su propia tumba.

De nuevo, un par de cifras sirven para ilustrar lo ocurrido. En el Foro Económico realizado en Davos (Suiza) en enero de 2015, la organización Oxfam informó que la centralización de la riqueza en el mundo crece a tal ritmo que si en el año 2010 las 80 personas más ricas, según la revista Forbes, poseían una riqueza neta de US $\$ 1,3$ billones, para 2014 ese monto ascendía a US $\$ 1,9$ billones, lo que equivale a lo poseído por el 50\% más pobre de la Tierra. Como destaca una nota de prensa, "esto quiere decir que 3.500 millones de personas comparten la misma cantidad de riqueza que estas 80 personas enormemente ricas" (La República, 2015:12). Para 2016, la fortuna conjunta de los 80 mil millonarios más ricos asciende a más de dos billones de dólares. Mientras, la riqueza de la mitad más pobre de la población del planeta se ha reducido en aproximadamente un billón 
de dólares en los últimos cinco años, de modo que en la actualidad sólo 62 ricos milmillonarios poseen la misma riqueza que la mitad más pobre de la población mundial (3.600 millones de personas).

\section{EL CAPITALISMO MONOPOLISTA: BASE DE LA CONSOLIDACIÓN DE LAS EMPRESAS TRANSNACIONALES}

En el acápite anterior se vio cómo la concentración de la producción y la centralización del capital -procesos ineludibles en el capitalismo, gracias, en gran parte, a las «revoluciones industriales»-generan la gran empresa -que tampoco, per se, es perjudicial, pues permite utilizar el avance científico-técnico para abaratar los costos y mejorar la calidad-, pero que tiene la posibilidad de convertirse en monopolista, si puede imponer ciertas condiciones en un mercado, ya sea sola o en alianza, pública o secreta, con otras empresas. En un momento tan temprano del desarrollo capitalista como 1890, en Estados Unidos se promulgó la primera ley antimonopolista, la conocida Sherman Act o Anti-trust Law. Luego, en 1914 se promulgó la Clayton Act que declaró ilegales cuatro tipos de prácticas monopolistas o restrictivas del mercado (Gaviria Cadavid, 2005: 226-228). Como lo evidencia el transcurso de más de un siglo, ninguna «ley jurídica» ${ }^{\mathbf{6}}$, en ninguna parte, ha impedido que «rija» la «ley económica» ${ }^{7}$ que impone la transformación del inicial capitalismo de libre competencia en el actual capitalismo monopolístico, sin que desaparezca la competencia, aunque sí cambie de contenido ${ }^{8}$.

A principios del siglo 20 el político ruso Vladímir Ilich Uliánov (1870-1924), más conocido por su seudónimo de Lenin, resumió así la historia de este proceso desde la segunda parte del siglo 19 -recuérdese que el primer tomo de El Capital se publicó en 1867-: “1) Décadas del 60 y 70, punto culminante de desarrollo de la libre competencia. 2) Después de la crisis de 1873, largo periodo de desarrollo de los cartels, los cuales sólo constituyen todavía una excepción, no son aún sólidos, aún representan un fenómeno pasajero. 3) Auge de fines del siglo XIX y crisis de 1900 a 1903: los cartels se convierten en una de las bases de toda la vida económica”. Como plantea a continuación Lenin (1980: 180), el "capitalismo se ha transformado en imperialismo. Los cartels convienen entre sí las condiciones de venta, los plazos de pago, etc. Se reparten los mercados de venta. Fijan la cantidad de productos a fabricar. Establecen los precios. Distribuyen las ganancias entre las distintas empresas, etc.”. Circunstancias que, bajo condiciones un poco distintas a las «vistas» por Lenin, ocurren con mayor celeridad en países de capitalismo dependiente y atrasado, pero oligárquico, como, en términos generales, sucedió en los principales países de América Latina -para mencionar una región cercana-, o de manera más específica en Colombia.

6. Entendida como regla o norma suprema promulgada por la autoridad competente; en este caso, el Congreso u órgano legislativo en los Estados modernos.

7. Entendida como regla o norma que nace de las cualidades de una cosa; en este caso, la actividad económica

8. Se considera que esta transformación se inició en la segunda parte del siglo 19 y no ha concluido, para dar paso a una etapa diferente. 
Como a mediados del siglo 20 lo dirá el profesor Paul A. Samuelson (1915-2009), premio Nobel en Economía en 1970, "La realidad es que muchas de las alabanzas dedicadas al sistema de competencia están fuera de lugar, porque, como hemos dicho antes, el nuestro es un sistema mixto de competencia y monopolio. Un cínico podría decir de la libre competencia lo que Bernard Shaw dijo, en cierta ocasión, del cristianismo: que su único defecto consiste en que nunca ha sido puesto en práctica. Jamás ha existido un siglo de oro de la libre competencia, y hoy día la competencia no es perfecta en el sentido económico, e incluso, probablemente, cada vez lo es menos, debido en gran parte a la índole peculiar de la producción en gran escala y a la técnica, a los gustos de los consumidores y a la organización comercial".

Como decía Samuelson (1967: 40-41 y 80-81) en ese momento, por "su número, la forma dominante de la empresa en los Estados Unidos es la de tipo pequeño, transitorio y de propiedad individual. Pero atendiendo a su valor, potencia económica y política, nóminas que pagan y empleos que proporcionan, la realidad es que unas cuantas centenas de empresas gigantes ocupan una estratégica posición dominante en la moderna economía norteamericana". Sistema en el que, como lo ha corroborado la historia posterior hasta principios del siglo 21, cada vez pesa más el monopolio con su competencia simulada o concertada entre aparentes competidores.

Un teórico de la administración, como el español José-Carlos Jarillo reconoce de entrada en uno de sus libros más conocidos que «mercados de competencia perfecta» no existen y al revisar las características que debe tener tal tipo de mercado, concluye: "Evidentemente, no hay ningún negocio que cumpla al pie de la letra estas condiciones: por ello hemos dicho que éste es un planteamiento teórico. (...) en un mercado de competencia perfecta es absolutamente imposible obtener, a medio y largo plazo, beneficios reales. Siempre que éstos aparezcan, la entrada de nuevos competidores, unida a la sensibilidad al precio de los clientes, se encargará de rebajar los márgenes hasta que desaparezcan los beneficios empresariales. Esta idea, tan simple, es absolutamente fundamental a la hora de entender cómo y por qué se gana dinero, y estará constantemente presente a lo largo de este libro". Y al hablar de mercados de monopolio, como la industria farmacéutica con patentes (una fuerte barrera de entrada), dice que es "precisamente porque no son perfectos por lo que se gana dinero en ellos. La base de la capacidad de obtener beneficios en un sector determinado está en las imperfecciones de ese sector, en aquellas características estructurales que lo diferencian de un mercado de competencia perfecta. (...) El resto del libro se dedicará a ilustrar, de un modo eminentemente práctico, cómo se pueden utilizar esas imperfecciones para asegurar beneficios empresariales duraderos”. Y más adelante aclara: “(...) Lo que una empresa necesita para poder asegurarse beneficios a largo plazo es una ventaja competitiva sobre sus competidores. Una ventaja competitiva es cualquier característica de la empresa que la aísla de la competencia directa dentro de su sector. (...) Por eso consideramos la estrategia competitiva como el conjunto de acciones que una empresa pone en práctica para asegurarse una ventaja competitiva sostenible" (Jarrillo, 1990: 3, 5, $6,23,35,186$ y 187). 
Lo que olvida este racionamiento es que ésta es la lógica del desarrollo capitalista, lógica que incluso alcanzó a señalar Carlos Marx, aunque él no pudo ver el paso del capitalismo de libre competencia al capitalismo monopólico. Para Marx era claro que la introducción de tecnología rebaja los costos, pues reduce el tiempo de trabajo necesario, aunque con frecuencia esta reducción del valor no se traduce en reducción del precio final, como debería ser, sino se convierte en mayor ganancia del empresario. Por tanto, no siempre la consecuencia de la alta concentración serán precios altos, pues la «ventaja de costos» puede llevar a «cobrar un precio más bajo», al tiempo que se obtiene «un mayor margen de ganancia». Es decir, la reducción de costos que conlleva la productividad puede facilitar el surgimiento de monopolios, los que pueden manejar el nivel de precios a su arbitrio, ya que controlan algunas condiciones del mercado. En la realidad del desarrollo capitalista de Colombia se han visto casos que manejan esta lógica, en productos ya mencionados como el azúcar, el cemento, las gaseosas, las cervezas, el tabaco, el chocolate y otros más, e incluso en algunos servicios. ¿Si esto no es monopolio, o sea abuso de una posición dominante de mercado, por costos, por calidad o por cualquiera otra razón, cómo puede llamarse?

En las páginas anteriores se ha mostrado que el surgimiento de los monopolios no es una deformación del capitalismo sino un resultado lógico de su desarrollo, pero, al mismo tiempo, la alta concentración de la producción y centralización del capital que facilita el monopolio, es una de sus contradicciones fundamentales, pues niega la propiedad privada, que permite que el excedente se apropie de manera individual (así ese «individuo» sea un «colectivo»: el grupo de accionistas de una empresa), para dar paso a un nuevo tipo de propiedad, como ya lo intuyeron, entre muchos, Engels y Galbraith.

En su desarrollo los monopolios se expresan de diversas formas, sin que lleguen a ser el único agente económico en la respectiva actividad, pues siguen recurriendo a la modalidad de los cárteles u oligopolios ${ }^{9}$ para ejercer el control sobre un determinado mercado. Pueden ser horizontales -controlan en extensión el mercado de un bien o servicio-, verticales -controlan el proceso de producción, a veces desde el mismo suministro de materias primas hasta la distribución del producto final-, o diversificados, en que se combina ambas modalidades. Ya sea que utilicen formas tradicionales o nuevas de funcionamiento, como un nivel superior de integración de diversos monopolios ubicamos a los conglomerados, que expresan, en lo fundamental aunque no en forma exclusiva, el proceso de concentración de la producción. Y en la cúspide, como materialización de la oligarquía financiera, a los grupos financieros, que expresan, en esencia, la máxima centralización del capital.

9. No se ve al oligopolio como una situación diferente al monopolio, como lo proponen algunos tratadistas, sino como una modalidad de monopolio compartido. El Diccionario de Economía de Arthur Seldon y F. G. Pennance (Orbis, Barcelona, 1983) define el oligopolio así: "Aquella situación de mercado en que un producto lo suministran un pequeño número de empresas cuyas actividades y políticas vienen determinadas por las reacciones esperadas de las otras empresas que componen este mercado. La esencia del oligopolio consiste en la interdependencia mutua entre las empresas (...)”. 
Para resaltar la importancia de la inversión transnacional, esto es, aquella que va más allá de la nación de origen, buscando los mercados de otras naciones, el gurú de la teoría administrativa, Peter Drucker, recordaba en los años noventa del siglo pasado que "cerca de una quinta parte del capital total invertido en firmas manufactureras en los Estados Unidos está en instalaciones fuera del país. Además, una proporción parecida de la producción de las industrias manufactureras de los Estados Unidos se está haciendo en el exterior. Tres cuartas partes de esa producción es para la venta en el extranjero, y una cuarta parte es para exportarla a los Estados Unidos y venderla o incorporarla en bienes para el mercado estadounidense" (Drucker, 1993:38-39...).

Como recuerda un investigador argentino, la "llamada «mundialización neoliberal» no es otra cosa que el sistema capitalista real actual, cuyo núcleo central es un puñado de grandes sociedades transnacionales que extienden sus redes de dominación sobre todo el planeta”. Según un estudio de 2011 del Swiss Federal Institute of Tecnology, de Zurich, "el grueso del poder económico mundial confluye en 737 grandes corporaciones, la mayoría de ellas bancos y grupos financieros que, a través de diversas redes y vínculos, controlarían el activo del 80\% de las grandes transnacionales. Pero según el mismo estudio, un grupo más concentrado, que llaman «super-entity», de sólo 147 corporaciones controlaría el 40\% de dicho activo" (Teitelbaum, 2012:14)

En confirmación de lo ocurrido entre finales del siglo 20 y principios del siglo 21, puede recordarse lo que dijo el pensador egipcio Samir Amin (1931- ), director del Foro del Tercer Mundo en Dakar (Senegal), en una entrevista reciente en respuesta a una pregunta sobre su visión del mundo actual. "Mi tesis sobre la naturaleza del sistema capitalista contemporáneo -que de modo más modesto la llamaré «hipótesis» porque está abierta a discusión-, es que hemos entrado a una nueva fase del capitalismo monopólico, (...) pautada por el grado de centralización del capital, cuya condensación llega a tal punto que, hoy en día, lo controla todo. (...) es un cambio cualitativo al que yo llamo de «monopolio generalizado», es decir, que se extiende a todas las esferas. [Pone como ejemplo la agricultura en los países capitalistas ricos, en donde los monopolios controlan desde la producción de semillas hasta las cadenas de comercialización] Esta característica provoca consecuencias sustantivas e importantes (...)"10.

\section{Monopolios y transnacionales en el capitalismo periférico y atrasado. Un caso específico: Colombia}

Pero el cuerpo teórico formulado por autores que escribieron sobre el capitalismo primigenio y en momentos anteriores a la segunda parte del siglo 20 no puede aplicarse de manera mecánica a los países que en la periferia del sistema se desarrollan dentro de las peculiaridades de un «capitalismo tardío», que en el marco de las leyes generales puede tener algunas expresiones específicas. En este sentido parece que hace falta avanzar en el estudio de la universalización de

10. Entrevista de Irene León a Samir Amín, recibida por correo electrónico del servicio informativo Alai-amlatina (http://alainet.org) el 30 de marzo de 2012. 
las relaciones sociales de monopolio, pero en condiciones distintas de como las analizaron esos autores, sobre todo Marx y sus continuadores, así muchos de ellos no se declaren marxistas en otros aspectos.

Vista la universalización que implica la creación del mercado mundial y el cambio cualitativo que significa haber pasado de la diferenciación de los capitalistas a la diferenciación de los Estados capitalistas -sin que desaparezca aquella-, se pueden entender con mayor facilidad los efectos del capital imperialista sobre la periferia dominada y la peculiaridad de los monopolios y el capital financiero surgidos en los países dependientes. Si se estudia con detenimiento el tránsito del mundo de la libre competencia al dominio monopolista, se ve que este tránsito, por ser la vía lógica de desarrollo del capitalismo también puede darse en el capitalismo dependiente, sin que este capital financiero pueda tener una política internacional imperialista. Es decir, que si bien el imperialismo sólo es posible en la época del capital monopolista, pues supone por necesidad una concentración de la producción y centralización del capital tal, que pueda proyectarse al exterior, en cambio el nacimiento de los monopolios, como una ley general del capitalismo, no es exclusivo de los países imperialistas, sino un fenómeno que puede ocurrir en cualquier país capitalista cuando se den ciertas circunstancias de acumulación y diferenciación. Esta afirmación puede sustentarse en el hecho real, pero poco destacado, de que los monopolios aparecieron en los países que Lenin llama imperialistas antes de que estos hubieran devenido en imperialismo.

Al tiempo que se acentuaba la desigualdad económica y política y se resquebrajaba la vieja base colonial, se aceleraba el desarrollo del capitalismo en los países periféricos, uno de los rasgos fundamentales del siglo 20. Por tanto, no es el estancamiento lo que podría llevar de manera ineluctable al capitalismo dependiente y atrasado a una situación de crisis, sino al contrario, su desarrollo en profundidad y extensión, lo que exacerba todas sus contradicciones. Por eso, lo que distingue a los países capitalistas pobres y atrasados de los ricos y avanzados no es el ritmo o velocidad del crecimiento -que en muchos casos puede ser mayor en los primeros-, sino el contenido y la forma de su capitalismo, pues también en éstos la concentración y la centralización van a permitir la acumulación en gran magnitud y la diferenciación de los capitalistas, hasta llegar a que algunas grandes empresas puedan proyectarse al exterior con la exportación de capital, sin que lleguen a ser expresión de imperialismo, en su forma tradicional.

Si bien el proceso de desarrollo capitalista destaca a la oligarquía financiera al primer plano, diferenciándola del resto de los capitalistas, no se funde en un bloque monopolístico y actúa dividida en complejos, consorcios y grupos financieros que compiten por una tajada mayor del excedente. De tal manera, estas nuevas categorías económicas, aunque impulsan la concentración de la producción y la centralización del capital, no eliminan la anarquía, el desarrollo desigual y la competencia, la que adquiere nuevos rasgos. El grupo financiero es la expresión material de la oligarquía financiera y como tal no corresponde a una forma particular del capital (capital-mercancía, capital-dinero o capital-productivo), sino que tipifica la fase en que se han fusionado. Tampoco está constituido como persona jurídica y por ello es muy difícil y casi imposible controlarlo de manera legal; está por encima de las empresas pero no es independiente de ellas. 
Al mismo tiempo, el capitalista financiero cambia en sentido cualitativo. Ya no es un empresario común, en el sentido de que dirige y está al frente de la producción, sino una especie de super empresario que representa el capital-propiedad, mientras el capital-función se delega en personas que pueden no ser capitalistas financieros. Tal es el caso de los altos ejecutivos, que participan del excedente (la plusvalía) no por medio de los rendimientos de las acciones -aunque a veces también son accionistas- sino de los sueldos exagerados y los jugosos beneficios extra salariales. Es fácil ver cómo las cabezas visibles de los grupos financieros no gerencian sus principales empresas; son emperadores que tienen generales que les hacen la guerra, testaferros que explotan en su nombre y amanuenses que escriben su historia.

Como se lee en la parte final del libro Los verdaderos dueños del país. Oligarquía y monopolios en Colombia, ya para mediados de los años setenta del siglo pasado era evidente en Colombia un nivel alto de monopolización (concentración de la producción y centralización del capital), llegando a un promedio que podría oscilar alrededor del 50\% para el conjunto de toda la economía, con niveles que irían del $10 \%$ en el comercio al $100 \%$ en el sector financiero y la producción de electricidad, gas y agua, $75 \%$ en la industria y $70 \%$ en comunicaciones, sin que estos porcentajes indiquen un grado exacto, pues siempre será difícil hacer tal medición con exactitud.

También en este libro se aclaraba que otro "hecho que hemos de tener en cuenta es que no siempre las empresas que forman parte de un grupo le pertenecen en exclusividad, ya que incluso a veces varios grupos comparten una empresa. También hemos de observar que en ciertos casos el control no se canaliza a través de la posesión de acciones, sino del otorgamiento de crédito. Por eso -y regresando a una idea ya expresada-, lo que permite identificar a una empresa como vinculada a un grupo financiero, no es tanto la posesión de un determinado monto de acciones, cuanto que obedezca al centro de orientación común, a la estrategia global. Puede decirse que el corazón de un grupo financiero son las empresas cuya materia prima es el capital-dinero o el capital ficticio (acciones)". Para 1974 los diez grupos financieros más grandes presentes en Colombia [incluidos tres extranjeros: Rockefeller, Morgan y First National City Bank] poseían activos bajo su control directo cercanos a 160.000 millones de pesos colombianos corrientes, lo que equivalía a una cifra cercana al 50\% del PIB, que para ese año sumó, en términos redondos, 325.000 millones de pesos corrientes (Silva-Colmenares, 1977: 303, 306 y 310).

Para principios del siglo 21 también los diez principales grupos financieros [ya no se identifican los grupos extranjeros como tales] habían multiplicado los activos bajo su control en más de 600 veces y sumaban un poco más de 97 billones de pesos corrientes, magnitud cercana al 50\% del PIB, lo que muestra que en los 25 años habían mantenido un férreo control sobre la economía colombiana. El principal grupo en ese momento correspondía al que desde los años setenta fue «bautizado» como grupo Suramericana, y que algunos llaman el Sindicato Antioqueño y otros el Grupo Empresarial Antioqueño, con unos activos equivalentes al $15,7 \%$ del PIB, unos 11.500 millones de dólares estadounidenses, cuando en los años setenta ocupaba el cuarto puesto, con activos equivalentes al 7,3\% del PIB; es decir, más que duplicó su peso relativo. Le seguía el grupo Santodomingo con 
activos equivalentes al 10,9\% del PIB, unos 8.000 millones de dólares, cuando en los años setenta tenía el 4,6\%; o sea que también más que duplicó su peso relativo. En tercer lugar estaba el grupo Sarmiento Ángulo con activos equivalentes al 10,5\% del PIB, unos 7.700 millones de dólares, cuando en los años setenta, cuando se le identificó como grupo Bogotá, tenía el 9\%. Como se lee en El gran capital en Colombia, algunos de los grupos que figuraban en los años setenta del siglo pasado desaparecieron como grupo, "aunque la mayoría de las empresas que eran insignia en su momento sólo han cambiado de «dueño». Esta es la característica principal en el fenómeno de la centralización del capital en Colombia: cambia la forma, la apariencia, pero se consolida y fortalece el contenido, la esencia" (SilvaColmenares, 2004: 23-27).

Para finalizar esta acápite puede verse como un ejemplo de la transnacionalización del gran capital colombiano el caso del grupo Suramericana, el más grande que queda con base en Colombia, ya que se han podido identificar inversiones en el exterior de cuatro de sus principales conglomerados (Bancolombia en el sector bancario, Nutresa en alimentos, Sura en seguros, pensiones y cesantías y Argos en cemento, concreto, puertos y energía); este grupo, por ejemplo, acumulaba hasta finales del año 2014 inversión identificada por más de US\$13.700 millones, lo que equivale a casi el 31\%, o sea alrededor de un tercio de toda la inversión colombiana en el exterior registrada por el Banco de la República hasta ese año. Los activos registrados de sus cinco principales conglomerados sumaban al finalizar 2013 casi Col\$220 billones, lo que equivalía a más de la cuarta parte del Producto Interno Bruto de Colombia en ese año. Y tiene presencia directa desde Uruguay hasta el sur de los Estados Unidos, incluida toda Centroamérica y gran parte del Caribe. En el caso de Bancolombia, tiene 9 millones de clientes y 836 sucursales en Centroamérica, en donde maneja activos por US\$20.000 millones ${ }^{11}$.

\section{COLOMBIA: UN EJEMPLO DE ALTA Y CRÓNICA CENTRALIZACIÓN DEL CAPITAL}

En las páginas iniciales de este trabajo se dijo que la centralización en la propiedad de los medios de producción es un proceso inherente al desarrollo capitalista, estimulado por la acelerada introducción de ciencia y tecnología a la producción, Y que este proceso también ha estado presente en los países de la llamada periferia capitalista, quizá en forma más precoz y profunda. Para referirse al caso de Colombia, puede traerse a colación lo que el premio Nobel de Economía Paul Krugman (1953- ) dijo del libro del economista francés Thomas Piketty (1971- ): “(...) La gran idea detrás de El capital en el siglo XXI es que no sólo hemos retrocedido a los niveles de desigualdad de ingreso del siglo XIX, sino que también estamos en el camino de regreso al «capitalismo patrimonial», en el que los puestos de mando de la economía no están bajo el control de individuos talentosos sino de dinastías familiares" (Krugman, 2014: 11-12).

11. Véase más información sobre este grupo en Silva-Colmenares, Julio y Padilla-Pardo, Carolina. Transnacionalización de empresas colombianas. Conglomerados que cruzan fronteras. Editorial Universidad Autónoma de Colombia, Bogotá, 2015, pp. 55 a 98 
Esta es la situación predominante en muchos países pobres, casi desde su creación, y para Colombia se comprobó en los libros Los verdaderos dueños del país y El gran capital en Colombia, ya mencionados. En este último se mostró que si en 1975 siete grupos financieros colombianos controlaban activos que equivalían al 45\% del PIB, para el 2002 el control de diez grandes grupos equivalía a casi el 47\%, pero con una mayor centralización a favor de los más poderosos. Un estudio sobre el mercado de capitales en Colombia, realizado a principio de los años noventa del siglo pasado, encontró un coeficiente Gini de más de 0,9 para la posesión de acciones en la Bolsa de Colombia. Estos pocos grupos son manejados por familias bien identificadas en los dos libros y por no más de cien personas, que son muchísimo menos que el $0.1 \%$ (el milésimo) a que hace referencia Thomas Piketty ${ }^{12}$ y es el centro de atención de movimientos como Ocuppy Wall Street.

"Hoy, como ayer -se lee en El gran capital en Colombia-, la altísima centralización del capital no sólo nos confirma que el país sigue teniendo unos pocos pero verdaderos dueños, con la consiguiente concentración del ingreso, mientras en el otro lado de la moneda más de la mitad de la población padece la «enfermedad social» de la pobreza y su síndrome más grave, la miseria. Colombia fue durante el siglo 20 un «modelo» de sociedad excluyente y atrasada, con una economía cerrada y monopolizada" (Silva-Colmenares, 2004: 25 y 27). Y en la Introducción a Los verdaderos dueños del país se había dicho: "Pretendemos identificar en las páginas siguientes a las principales empresas que acaparan sectores fundamentales de nuestra economía, pero para ello no podemos valernos solamente de la palabra, esquiva a veces; equívoca, otras; es necesario hacer del número una categoría verbal y aunque su discurso es menos bello y armonioso, es más exacto y confiable" (Silva-Colmenares, 1977:7). Más de 30 años después Piketty dice: “Quienes tienen mucho nunca se olvidan de defender sus intereses. Negarse a usar cifras rara vez favorece a los más pobres". Y recuerda una bella frase con que empieza un libro publicado en 1965 sobre los beneficios empresariales en Francia en el siglo 19, y que reza así: “«Mientras los ingresos de las clases de la sociedad contemporánea sigan fuera del alcance de la investigación científica, será en vano querer emprender una historia económica y social de utilidad»" (Piketty, 2014: 647-649).

Trabajando sobre una idea similar a la que plantea Piketty, para quien el rendimiento del capital supera el ritmo a que crece la actividad económica, en un cálculo efectuado en el Observatorio sobre Desarrollo Humano de la Universidad Autónoma de Colombia ${ }^{13}$ se encontró que los activos de las veinte empresas más grandes de Colombia aumentaron, en precios corrientes, como es la contabilidad empresarial normal, en 119 veces entre 1986 y 2013, un periodo de 27 años, mientras el PIB, también en precios corrientes, aumentó en 93 veces. Para afianzar la

12. Véase su libro El capital en el siglo XXI, Bogotá, Fondo de Cultura Económica, 2014.

13. Cálculo efectuado por Carolina Padilla Pardo, Asistente-coordinadora del Observatorio e investigadora asociada en este proyecto. Es de aclarar que las veinte empresas no son las mismas en los dos momentos, sino las veinte con mayores activos en cada año, como se indica al pie de la tabla 1. 
idea sobre la velocidad en la acumulación, el patrimonio, que representa el capital propio de los dueños de las empresas, aumentó en 349 veces en el mismo lapso. La tasa anual geométrica para el incremento del patrimonio fue del $24,2 \%$, la de los activos del 19,4\% y del PIB del 18,3\%, tasas calculadas sobre valores corrientes, como puede verse en la tabla 1. Como es natural, la relación del patrimonio y los activos respecto al PIB aumenta, pasando, en el caso del patrimonio del 7,0\% al $26,5 \%$, y en los activos del $38,1 \%$ al $49,4 \%$.

Tabla 1

Colombia: Activos de las 20 empresas más grandes y PIB Años 1986 y 2013

(Billones de pesos corrientes)

\begin{tabular}{|c|c|c|c|c|}
\hline CONCEPTO & 1986 & 2013 & $\begin{array}{c}\text { TAG } \\
27 \text { años }\end{array}$ & $\begin{array}{c}\text { No. de } \\
\text { veces } \\
2013 / 1986 \\
\end{array}$ \\
\hline Activos de las 20 empresas más grandes del país* & 2,9 & 349,5 & $19,4 \%$ & 119,1 \\
\hline Patrimonio de las 20 mayores empresas por activos* & 0,5 & 187,5 & $24,2 \%$ & 349,1 \\
\hline PIB a precios corrientes & 7,6 & 710,3 & $18,3 \%$ & 93,2 \\
\hline Activos/PIB & $38,5 \%$ & $49,2 \%$ & & \\
\hline Patrimonio /PIB & $7,0 \%$ & $26,4 \%$ & & \\
\hline
\end{tabular}

TAG = Tasa anual geométrica o acumulativa.

Fuente: Para activos y patrimonio la revista Semana, en su informe anual sobre las mayores empresas de Colombia. Para el PIB el DANE.

*Para 1986 las empresas fueron: Ecopetrol, ISA, Carbocol, Intercor, Empresa de Energía de Bogotá, Empresas Públicas de Medellín, Empresa de Acueducto de Bogotá, Telecom, Cerromatoso, Flota Mercante Grancolombiana, Avianca, Bavaria, Acerías Paz del Río, Coltejer, Fabricato, Carvajal, Cartón de Colombia, Colmotores, Coltabaco y Propal. Para 2013 las empresas fueron: Argos, Nacional de Chocolates (Nutresa), Empresas Públicas de Cali, Emgesa, Codensa, Isagen, ETB, Comcel, Empresa de Acueducto de Bogotá, Electricaribe, Colombia Telecomunicaciones, Drummond, Pacific Rubiales y Celsia. Para esta lista se excluyeron entidades financieras y de comercio.

En resumen, el surgimiento del monopolio en nuestro medio no es un hecho casual o insólito, sino resultado lógico del desarrollo capitalista, aunque sean monopolios deformados por la dependencia y el atraso. No obstante, hemos de recordar que lo fundamental del capitalismo dependiente no es tanto tener monopolios cuanto que se desarrolla en la época de los monopolios transnacionales. La aparición de los monopolios en los principales renglones de la industria fue muy precoz, por lo que se comprueba con la experiencia colombiana que en el capitalismo dependiente y tardío no hay en la práctica una época de libre competencia. Tan peculiar génesis hace que el proceso de monopolización sea muy deformado y haya estimulado una temprana aparición del capital financiero y la oligarquía financiera, identificada en párrafos anteriores. 


\section{REFERENCIAS}

1. BORISOV, ZHAMÍN y MAKAROVA (1975). Diccionario de Economía Política. Ediciones Armadillo. Bogotá.

2. DRUCKER Peter (1993). Gerencia para el futuro. El decenio de los 90 y más allá. Norma, Bogotá.

3. ENGELS, Federico (1976). Del socialismo utópico al socialismo científico, en C. Marxy F. Engels, Obras Escogidas, tomo III, Editorial Progreso, Moscú.

4. SAMIR, Amín (2012). Alai-amlatina (http://alainet.org) el 30 de marzo de 2012- Entrevista de Irene León.

5. GAVIRIA CADAVID, Fernando (2005). Los monopolios, en Varios, Economía crítica, Academia Colombiana de Ciencias Económicas, Bogotá.

6. JARILLO, José-Carlos (1990). Dirección estratégica. McGraw Hill, Madrid.

7. KRUGMAN, Paul (2014). Por qué estamos en una nueva edad dorada. Gaceta del Fondo de Cultura Económica, No. 523, julio, pp. 11-12.

8. LA REPÚBLICA (2015). La mitad de la riqueza mundial quedaría en manos de 1\% de la población en 2016. 20 de enero, p. 12.

9. LENIN, Vladimir I. (1980). El imperialismo, fase superior del capitalismo, en: Obras escogidas. Progreso. Moscú.

10. MARX, Carlos (1946). El Capital. Crítica de la Economía Política. Tomo I. Fondo de Cultura Económica. México.

11. MARX, Carlos (1946). El Capital. Crítica de la Economía Política. Tomo Ill. Fondo de Cultura Económica. México.

12. MARX, Carlos y ENGELS Federico (1973). Manifiesto del partido comunista. Obras escogidas. Tomo I, Editorial Progreso. Moscú.

13. MARX, Carlos (1958). Miseria de la Filosofía. Respuesta a la Filosofía de la Miseria de Proudhon. Ediciones Inca. Buenos Aires.

14. OXFAM (2016). Una economía al servicio del 1\%. Acabar con los privilegios y la concentración de poder para frenar la desigualdad extrema. Informe NN. 210, 18 de enero. Disponible en línea: https://www.oxfam.org/sites/www.oxfam.org/files/file_attachments/bp210-economy-one-percenttax-havens-180116-es_0.pdf

15. PIKETTY, Thomas (2014). El capital en el siglo XXI. Fondo de Cultura Económica. Bogotá.

16. SAMUELSON, Paul A. (1967). Curso de economía moderna. Aguilar, Madrid, decimoquinta edición.

17. SMITH, Adam (1994). La riqueza de las naciones. Alianza Editorial, Madrid.

18. SILVA-COLMENARES, Julio (1977). Los verdaderos dueños del país. Oligarquía y monopolios en Colombia. Suramérica, Bogotá.

19. SILVA-COLMENARES, Julio (2004). El gran capital en Colombia. Proyección al siglo 21. Planeta, Bogotá.

20. SILVA-COLMENARES, Julio y PADILLA-PARDO Carolina (2015). Transnacionalización de empresas colombianas. Conglomerados que cruzan fronteras. Editorial Universidad Autónoma de Colombia, Bogotá.

21. TEITELBAUM, Alejandro (2012). EI Capitalismo por Dentro. LAGJS/Estudio temático LISDINYS/DS (ET004), octubre, p. 14, tomado el 20 de noviembre de 2012 de www.jussemper.org 